AUTHOR(S): R. E. Reinovsky and I. R. Lindemuth

SUBMITTED to 9th IEEE International Pulsed Power Conference Albuquerque, New Mexico, June 21-23, 1993

\title{
DISCLAIMER
}

This report was prepared as an account of work sponsored by an agency of the United States Government. Neither the United States Government nor any agency thereof, nor any of their employees. makes any warranty, express or implior, or assumes any legal liability or responsibility for the accuracy, completeness, or usefulness of any information, apparatus, product, or process disclosed, or represents that its use would not infringe privately owned rights. Reference herein to any specific commercial product, process, or service by trade name, trademark, manufacturer, or otherwise does not necessarily constitute or imply its endorsement, recommendation, or favoring by the United States Government or any agency thereof. The views and opinions of authors expressed herein do not necessarily state or reflect those of the United States Government or any agency thereof.

By acceptance of this arlicle the publisher ecognizes that the U.S Government retains a nonexclusive. royalty-tree license to publish or reproduce thif publistied form of this contribution. or to allow others to do so, for US Government purposes 


\title{
DESIGN CONSIDERATIONS FOR 100 MJ CLASS FLUX COMPRESSION PULSE POWER SYSTEMS*
}

\author{
R. E. Reinovsky and I. R. Lindemuth \\ Los Alamos National Laboratory \\ Group M-6, Mail Stop C970 \\ Los Alamos, New Mexico 87545 USA
}

\begin{abstract}
Introduction
With the cost of high performance, capacitor-discharge pulse power systems continuing around \$1-2 per joule and with energy requirements for experiments such as fast compression of magnetized plasmas ranging to $100 \mathrm{MJ}$ and beyond, the need for economical, super-energy pulse power systems is being recognized. Explosively powered flux compressors, capable of delivering $100 \mathrm{MJ}$ to a plasma physics experiment, can be designed, fabricated, and fielded at costs of less than $\$ 0.01 \mathrm{~J}$ per shot. While less economical than laboratory pulsed power systems, if system life exceeds a few hundred full-energy shots, explosive pulse power techniques allow initial experiments to be performed quickly and economically at energies that are prohibitively costly, and hence unavailable, using conventional techniques.

A variety of configurations for flux compressors suitable for 100-MJ operation can be considered. Among these, the disk configuration, pioneered by researchers at the All Russian Institute of Experimental Physics (VNIIEF, Arzamas-16, Russia) has demonstrated both high current and high energy capabilities. ${ }^{1,2}$
\end{abstract}

\section{Disk Flux Compressor Model}

The basic configuration of the disk flux compressor is shown in Fig. 1 where Figs. 1a and $1 \mathrm{~b}$ show conceptual variations of a single module of such a system. In Fig. 1a, the high explosive is in the shape of a flat disk, with thin metal walls on the opposing faces. ${ }^{1}$ Plane parallel armature modules with a flat disk of explosive are easy to construct and are easy to analyze, but such shapes do not lead to best overall performance. Figure $1 \mathrm{~b}$ shows a practical cavity shape suggested by Chernyshev ${ }^{2}$ and reported by researchers at VNIIEF to be an efficient system for producing currents in excess of $100 \mathrm{MA}$ and energies in excess of 100 MJ. To explore behavior of the disk configuration in detail, a phenomenological model of its behavior has been developed. A description of that model has been reported previously ${ }^{3}$ and here we discuss some of the impacts on system design that emerge from application of that model.

\section{Cavity Configuration and Compression}

In order to operate effectively, the motion of the cavity walls must be such that the cavity is smoothly compressed starting at the inner-most radius and proceeding toward the outer radius. Since the magnetic field at smaller radii is higher than the magnetic field at larger radii, the magnetic pressure increases more rapidly at smaller radii than it does at larger radii. Thus, as the current increases, it is expected that the axial motion of the cavity walls will be more strongly affected by magnetic pressure at small radii and that

*This work supported by the US Department of Energy. 
system performance may be limited by the occurrence of "flux pockets." Pocketing occurs when the axially moving walls at larger radii have met on the centerline before all the fluxcontaining volume at smaller radii has been swept out. The Gurney model ${ }^{3}$ of wall motion assumes (almost) instantaneous wall acceleration followed by coasting motion. That is, after an initial push, the explosive products do little additional work on the system. In this approximation, only the magnetic pressure and wall momentum are required to completely describe the wall motion during most of the compression process and it is possible for the magnetic pressure to stop or even reverse the motion of the walls.

The simplest configuration for the disk flux compressor uses a flat disk of explosive initiated on the axis (Fig. 1a). The detonation front sweeps radially outward and the cavity collapses first on the axis with the contact point moving radially outward. Calculations of the motion of a flat 2-mm-thick copper wall, propelled by an 8-mm-thick slab of a common high explosive (60\% RDX, $40 \%$ TNT) are shown in Fig. 2. The cavity is (nearly) a right circular annulus with inner radius of $2 \mathrm{~cm}$ and outer radius of $20 \mathrm{~cm}$. In fact, the axial length of the cavity is $1-\mathrm{mm}$ longer at the $20-\mathrm{cm}$ radius $(21 \mathrm{~mm})$ than it is as the $2-\mathrm{cm}$ radius $(20 \mathrm{~mm})$. Although the model is capable of treating sloping end wall, perfect cylindrical glide surfaces at 2 and $20 \mathrm{~cm}$ are used in the calculation The initial inductance of the half-cavity is $9.38 \mathrm{nH}$, and the flux is compressed into a $0.25-\mathrm{nH}$ load $(0.5 \mathrm{nH}$ for a full cavity). The lossless current gain for the cavity is about 38.5. The wall motion calculations are performed using the phenomenological model and include flux diffusion and ohmic heating losses in the copper wall.

Figure 2a shows the motion of the wall when the cavity is initially loaded with 1-MA current. The compression of the cavity occurs smoothly and a peak current of $32.38 \mathrm{MA}$ occurs at $32.55 \mu \mathrm{s}$. Approximately $84 \%$ of the initial flux is compressed into the load. As the initial current is increased, peak current increases but ohmic heating of the conductor means that more flux is lost into the conductors during operation. Maximum currents of about $122 \mathrm{MA}$ is predicted with 5-MA initial currents for a flux efficiency of about $63 \%$. Above $5 \mathrm{MA}$, the magnetic pressure near the inner radius significantly slows and eventually stops the axial motion of the armature beginning the formation of a flux pocket. Figure $2 \mathrm{~b}$ shows five wall positions for an extreme case where the initial current is $12 \mathrm{MA}$. By $15 \mu \mathrm{s}$, the wall at radii smaller than about $5 \mathrm{~cm}$ has reversed direction under the influence of magnetic pressure and is expanding. At $15.12 \mu \mathrm{s}$ the wall reaches the centerline at about $5 \mathrm{~cm}$, contacts the adjacent wall and traps about $37 \%$ of the flux in the pocket at the time of closure. The peak current produced in the load is about $119 \mathrm{MA}$, and the overall flux efficiency is only $26 \%$.

Figure 3 shows the current delivered to the load as a function of initial current in the cavity. Flux pocketing does not occur at an initial current of $5 \mathrm{MA}$. A minor pocket is observed at initial currents of 5.5 MA. But even with the pocket a slightly higher peak current $(123 \mathrm{MA})$ is observed. Above 5.5 MA the increase in initial loading actually results in a decrease in current delivered to the load

Some of the difficulties of flux pocketing can be overcome by appropriately shaping the compression cavity. A simple, but effective, shape is shown in Fig. 4. The initial inductance at this shaped cavity is lower ( $8.06 \mathrm{nH}$ for half-cavity) than the planar cavity in Fig. 2. Thus the current gain is lower (33.2) and 1-MA initial current produces 27.6MA peak current. About $83 \%$ of the initial flux is compressed into the load. However the shaped cavity can be operated at initial current up to $8 \mathrm{MA}$ without substantial pocketing. At $8 \mathrm{MA}$ the peak current to the load was $170.7 \mathrm{MA}$ (almost $40 \%$ greater than the peak observed in Fig. 3). For higher initial currents pocketing occurs at small radius, beginning to appear at $8.5 \mathrm{MA}$. For initial currents, between 8 and $10 \mathrm{MA}$, the peak load current is 163-164 MA.

In principle, the flat disk of explosive shown in Fig. 2 could be initiated across its end surfaces instead of on the axis. In this case the copper wall would be accelerated more nearly as a flat plate resulting in faster compression of the cavity. This might be expected 
to lead to lower losses and perhaps less susceptibility to flux pocketing. To explore this possibility, the same (nearly) right circular cavity from Fig. 2 was employed. Initiation of the explosive on its face was approximated by increasing the radial velocity of detonation of the explosive 100 fold. Results are shown in Fig. 5. At 1-MA initial current, cavity compression proceeds smoothly, is complete in about $10 \mu \mathrm{s}$. However the peak current was only about $31 \mathrm{MA}$ in the 0.25-nH load (as compared with $32.4 \mathrm{MA}$ in Fig. 2). As discussed previously, ${ }^{3}$ we account for shock heating in the conductor by decreasing the conductivity of the wall by about 50\% after shocking. In Fig. 5 the entire conductor is shocked during the entire compression process (where in Fig. 2, part of the conductor is cold during much of the compression process). We see that the increased flux losses arising from decreased conductivity of the shocked walls more than compensates for the expected decrease in losses from faster operating times.

As the initial current is increased, however, we observe more severe flux pocketing. At $5 \mathrm{MA}$ (where the sweeping detonation case in Fig. 2 was delivering $122 \mathrm{MA}$ to the load), a substantial pocket forms at $11 \mu \mathrm{s}$ as shown in Fig. 5b and the peak current in the level is only about $55 \mathrm{MA}$. While the pocket in Fig. 5b appears to be smaller than the pocket in Fig. 2b, the remaining volume in the cavity at the time of pocket formation is also smaller and the overall flux efficiency is about the same $26 \%$.

As a general observation, the Gurney model assumes that the explosive products cannot impart significant impulse to the wall after the initial push. While this is a good assumption for a plate that flies freely after initial acceleration, this assumption may not be accurate if the plate is subsequently slowed (as by magnetic field). Thus, the model, as applied here, may overestimate the impact of magnetic pressure on wall motion and may exaggerate the flux-pocketing problem. A complete magnetohydrodynamic calculation with good equation of state (EOS) information during the release of explosive products is required to fully address this issue. The fact that the required EOS information during release is not readily available for most explosives complicates the problem. While such calculations have been performed in the absence of magnetic pressure ${ }^{3}$ the complete problem has not yet be calculated.

\section{Effects of Explosive Quantity and Proffle}

The efficiency of conversion of explosive to electrical energy is technically interesting but is not significant practical concern for small and medium-sized systems. For large systems, total charge mass and conversion efficiency may limit the total electrical energies that are ultimately achievable. As an example of a larger system, we consider a disk configuration with $50-\mathrm{cm}$ radius (two and one-half times larger than those considered above). Figure 6 shows the result of three calculations in which the interior wall contour, wall thickness, and initial current loading of a 50-cm-radius disk configuration is maintained and adjustments are made in the explosive configuration. The first case is a baseline case that results in smooth compression of the cavity. In the second case, the overall thickness of the explosive is decreased from $12 \mathrm{~mm}$ at small radii to $5 \mathrm{~mm}$. The total mass of the explosive is reduced to almost half, the apparent efficiency increases, but flux pocketing leads to dramatically reduced actual performance. The lower charge mass has lead to lower initial wall velocities and a turnaround in wall motion as the magnetic pressure begins to climb. In the third case, the inner explosive thickness is increased from $5 \mathrm{~mm}$ (as in the second case) to $6 \mathrm{~mm}$, and that 6 -mm thickness was retained all along the entire cavity wall by inserting an inert wedge near the outer radius of the system. This dramatically reduces the explosive charge (to approximately $25 \%$ of the baseline case) while retaining enough explosive to smoothly compress the cavity. The results of these calculations are summarized in Table 1. For the case of the shaped explosive, the efficiency of conversion of explosive to electrical energy is seen to be in excess of $25 \%$. At this efficiency, a 1-GJ electrical energy source would require only $800 \mathrm{KG}$ of explosive. 
TABLE 1

\begin{tabular}{lccc}
\hline & Nominal & Thinned & Shaped \\
\hline Explosive & & & \\
\hline Per Stage & $59.0 \mathrm{KG}$ & $41.6 \mathrm{KG}$ & $14.9 \mathrm{KG}$ \\
Four Stages & $236 \mathrm{KG}$ & $166 \mathrm{KG}$ & $59.6 \mathrm{KG}$ \\
Electrical & & & \\
\hline Peak Current & $283 \mathrm{MA}$ & $278 \mathrm{MA}$ & $275 \mathrm{MA}$ \\
Energy & $106 \mathrm{MJ}$ & $103 \mathrm{MJ}$ & $100 \mathrm{MJ}$ \\
Operating Time & $54.7 \mu \mathrm{s}$ & $55.1 \mu \mathrm{s}$ & $55.4 \mu \mathrm{s}$ \\
Efficiency & & & \\
\hline Elect/Explosive & $9.3 \%$ & $12.9 \%$ & $35 \%$ \\
Flux & $86.0 \%$ & $84.5 \%$ & $83.4 \%$ \\
\hline \hline
\end{tabular}

\section{Effects of Explosive Performance}

The details of explosive performance (detonation velocity and energy) are significant determiners of performance for some flux-compressor geometries. The impact of explosive performance for the representative disk configuration was evaluated by comparing the electrical performance of three geometrically identical generator configurations powered by three representative explosives: PBX-9501 (a high-performance, HMX-based plastic bonded explosive); Composition B (a medium performance TNT and RDX-based explosive in a wax base); and Nitromethane (a relatively low energy liquid that can, with difficulty, be driven to mass detonate). The cavity inductance was about $7.2 \mathrm{nH}$ and the load inductance was $0.4 \mathrm{nH}$ for a lossless current gain of 19. For each calculation, the current produced in the load was used as the indicator of performance. The R-Z behavior of each system was checked and the initial current loading was adjusted to roughly optimize the delivered energy while assuring that significant flux pocketing did not occur. For real explosives, high-detonation velocity and high energy are linked. To separate the influence of these two parameters, two mock explosives were also calculated: HE-1 has the slow detonation velocity of Nitromethane but the high energy of PBX-9501, and HE-2 has the high-detonation velocity of PBX-9501 but the low energy of Nitromethane. The results of these calculations are presented in Table 2 . The table shows that higher detonation velocity leads to slightly increased performance (because less time is allowed for flux to diffuse into the wall) and higher detonation energy likewise provides somewhat better performance. In general, the lowest performance real explosive produced about $44 \%$ of the energy in the load compared with the high performance real explosive.

TABLE 2

\begin{tabular}{|c|c|c|c|c|c|c|c|c|}
\hline & \multicolumn{4}{|c|}{ Explosive Properties } & \multicolumn{4}{|c|}{ Electrical Performance } \\
\hline & $\begin{array}{c}\mathrm{Vel} \\
\mathrm{km} / \mathrm{s}\end{array}$ & $\begin{array}{l}\text { Dens } \\
\mathrm{gr} / \mathrm{cc}\end{array}$ & $\begin{array}{l}\text { Gurney } \\
\text { Energy }\end{array}$ & $\begin{array}{c}\text { Weight } \\
\mathrm{kg}\end{array}$ & $\begin{array}{c}\text { Initial } \\
\text { MA }\end{array}$ & $\underset{\mu \mathrm{s}}{\text { Time }}$ & $\begin{array}{l}\text { Current } \\
\text { MA }\end{array}$ & $\begin{array}{c}\text { Energy } \\
\text { MJ }\end{array}$ \\
\hline $\begin{array}{l}\text { PBX-9501 } \\
\text { Comp-B } \\
\text { Nitro Methar } \\
\text { Mock HE-1 } \\
\text { Mock HE-2 }\end{array}$ & $\begin{array}{l}8.8 \\
7.9 \\
6.3 \\
6.3 \\
7.9 \\
\end{array}$ & $\begin{array}{l}1.85 \\
1.72 \\
1.13 \\
1.85 \\
1.13\end{array}$ & $\begin{array}{l}2.9 \\
2.7 \\
2.4 \\
2.9 \\
2.4\end{array}$ & $\begin{array}{l}5.5 \\
5.1 \\
3.4 \\
5.5 \\
3.4\end{array}$ & $\begin{array}{l}7.2 \\
6.8 \\
5.0 \\
7.0 \\
4.0\end{array}$ & $\begin{array}{l}21.7 \\
24.0 \\
30.0 \\
28.8 \\
24.7\end{array}$ & $\begin{array}{l}101 \\
94.7 \\
68.4 \\
99.4 \\
54.7\end{array}$ & $\begin{array}{l}4.08 \\
3.58 \\
1.87 \\
3.95 \\
1.20\end{array}$ \\
\hline
\end{tabular}




\section{Effects of Flux Diffusion}

Assuming that dynamic failures such as flux pocketing in disk systems are eliminated, loss of magnetic flux by diffusion into the walls represents the next most significant limitation to flux-compressor performance. In general, flux diffusion in real flux compressors with thick walls is a non-linear process involving non-uniform current density distribution in the walls, which leads to non-uniform heating and non-uniform changes in wall conductivity. However, to explore the diffusion effects, apart from the heating effects, it is possible to compare system performance with thick walls of uniform conductivity. Figure 7 compares system performance for a representative geometry with uniform, time-invariant wall conductivities. Three values of conductivity are compared: a high value, $5 \times 10^{8}$ $\mathrm{MHO} / \mathrm{M}$, which is about 1000 times the room temperature conductivity of copper; an intermediate value, $5.5 \times 10^{5} \mathrm{MHO} / \mathrm{M}$, characteristic of real, high-purity copper; and a somewhat lower value, $3.6 \times 10^{5} \mathrm{MHO} / \mathrm{M}$, characteristic of real aluminum. The high value of conductivity, ciuracteristic of a near-perfect conductor, produces system performance close to that of a lossless circuit model. More interesting, perhaps, is the comparison of copper and aluminum conductivities (two materials commonly used in flux compressors, although all high-performance disk systems reported to date have used copper cavities). The degradation in performance between copper and aluminum is seen to be only a few percent.

\section{Effects of Ohmic Heating in Walls}

In real systems, ohmic heating accelerates flux diffusion to some extent by decreasing the conductivity of the wall material near surface where the currents are concentrated. At low currents this effect is minimal and as currents increase the effect of wall heating becomes more significant. Figure 12 shows the impact upon system performance as the total current level is increased. For these calculations, the representative geometry was retained. Explosive performance was constant. The temperature-dependent conductivity of the copper walls was obtained from a combination of handbook data and information from the SESAME library. Current delivered to the load is again the measure of system performance. The three calculations are performed at three different initial curients: $1 \mathrm{~A}$, representing a case where resistive heating is insignificant; $700 \mathrm{KA}$, representing an intermediate initial flux; and $7 \mathrm{MA}$, representing the maximum initial current that avoids flux pocketing. The plot expresses performance as system gain, I/lo, and shows that the ohmic heating induced losses are almost undetectable up to nominal operating c conditions (up to about $6 \mathrm{MA}$ ), but become considerable as the initial current is increased beyond those nominal conditions.

\section{Conclusions}

The disk flux compressor represents an attractive approach to powering plasmaphysics experiments at energy levels above $100 \mathrm{MJ}$. Flux pocketing can have significant impact on system performance by limiting the maximum allowable initial current. Shaped cavities offer some advantages over right circular cavities, but still can suffer from pocketing. In our calculations, aerial initiation neither lowered losses nor relieved pocketing. Control of the amount and shape of the explosive can resul in relativoly large efficiencies of converting chemical to electrical energy. The performance of the explosive can have measurable impact on system performance, although proper design (quantity and profile) of the explosive can readily overcome small differences in explosive performance. The initial conductivity of the wall (e.g. copper or aluminum) is expected to have a few percent effect in overall performasse. 


\section{References}

1. A. I. Pavlovskii, R. Z. Lyudaev, B. A. Boyko, A. S. Boriskin, A. S. Kravchenko, V. E. Gurin, and V. I. Mamyshev, "Investigation of Disk Magnetocumulative Generators," Megagauss Fields and Pulsed Power Systems, Nova, (1990), p. 331.

2. V. K. Chernyshev, B. E. Grinevich, V. V. Vahrushev, and V. I. Mamyshev, "Scaling Image of $\sim 90 \mathrm{MJ}$ Explosive Magnetic Generators," Megagauss Fields and Pulsed Power Systems, Nova, (1990), p. 347.

3. R. E. Reinovsky, I. R. Lindemuth, S. P. Marsh, E. A. Lopez, "Explosive Pulse Power for Fusion Applications," Proceedings of 6th International Conference on Megagauss Fields and Applications, Albuquerque, (1992).

4. V. A Demidov, A. I. Kraev, V. I. Mamyshev, A. A. Petrukhin, V. P. Pogorelov, V. K. Chernyshev, V. A. Shevtsov, V. I. Shpagin, "Three Module Disk Explosive Magnetic Generator," Megagauss Fields and Pulsed Power Systems, Nova, (1990), p. 351. 
Fig. 1. Basic disk flux compressor configurations: (a) flat, (b) contoured

Fig. 2. Cavity compression with radially sweeping detonation. 12-MA initial current shows extreme pocket formation.

Fig. 3. Current delivered to load as function of initial current. Pocketing is observed for $\mathrm{I}_{o}>5.0 \mathrm{~mA}$.

Fig. 4. Cavity compression in contoured cavity with radially sweeping detonation. At 8.5 MA a pocket is beginning to form. Impact on references is slight.

Fig. 5. Cavity compression in flat cavity with simultaneous detonation.

Fig. 6. Explosive shaping and con touring cases for Table 1.

Fig. 7. Current delivered to load with three way conductivities, without ohmic heating.

Fig. 8. Current delivered to load with ohmic heating. 


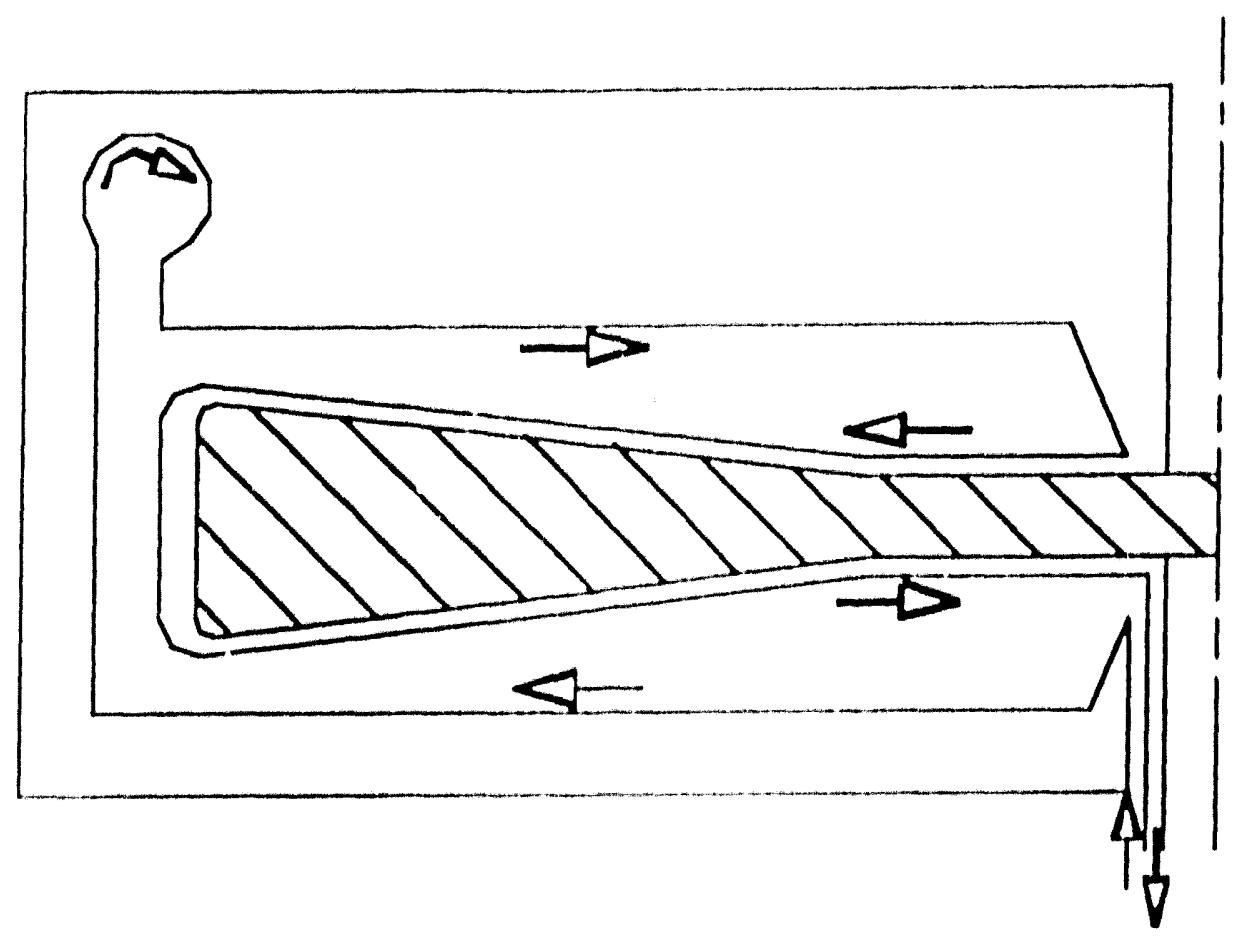

11

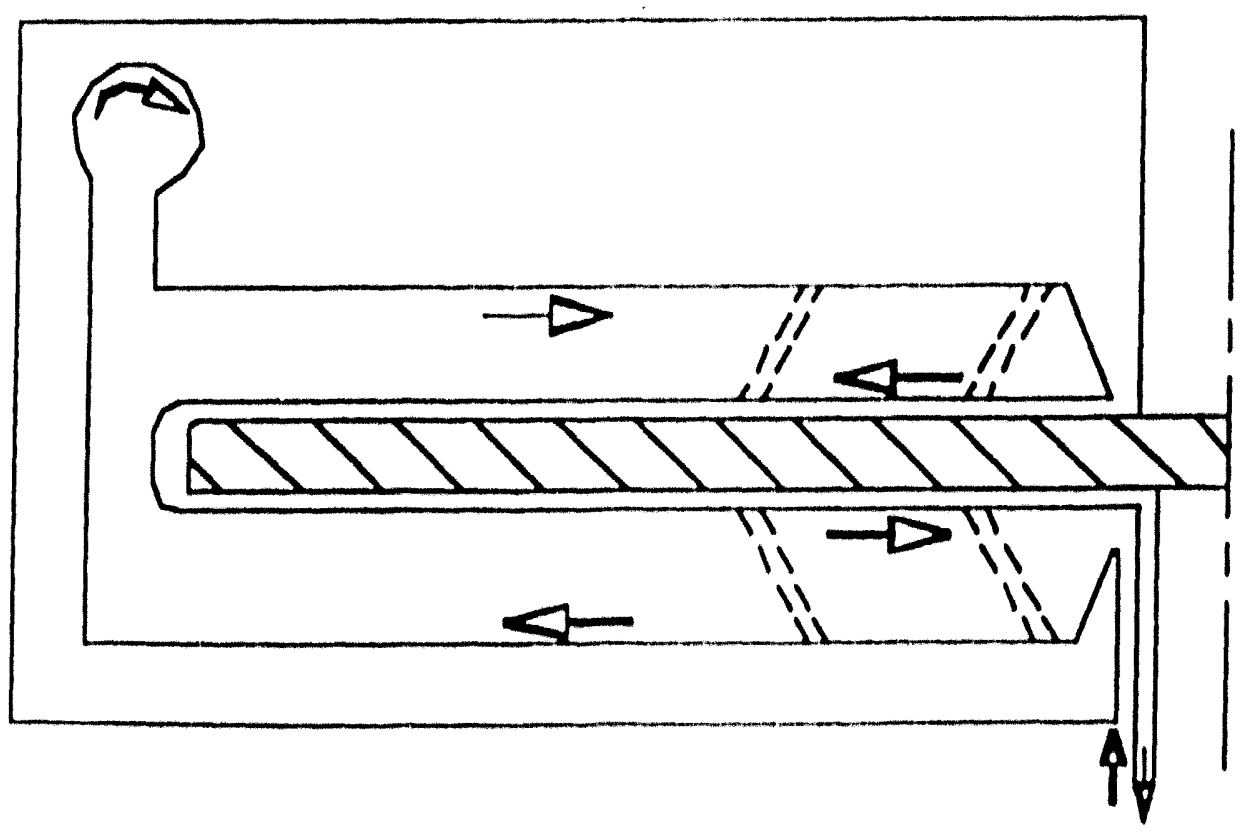




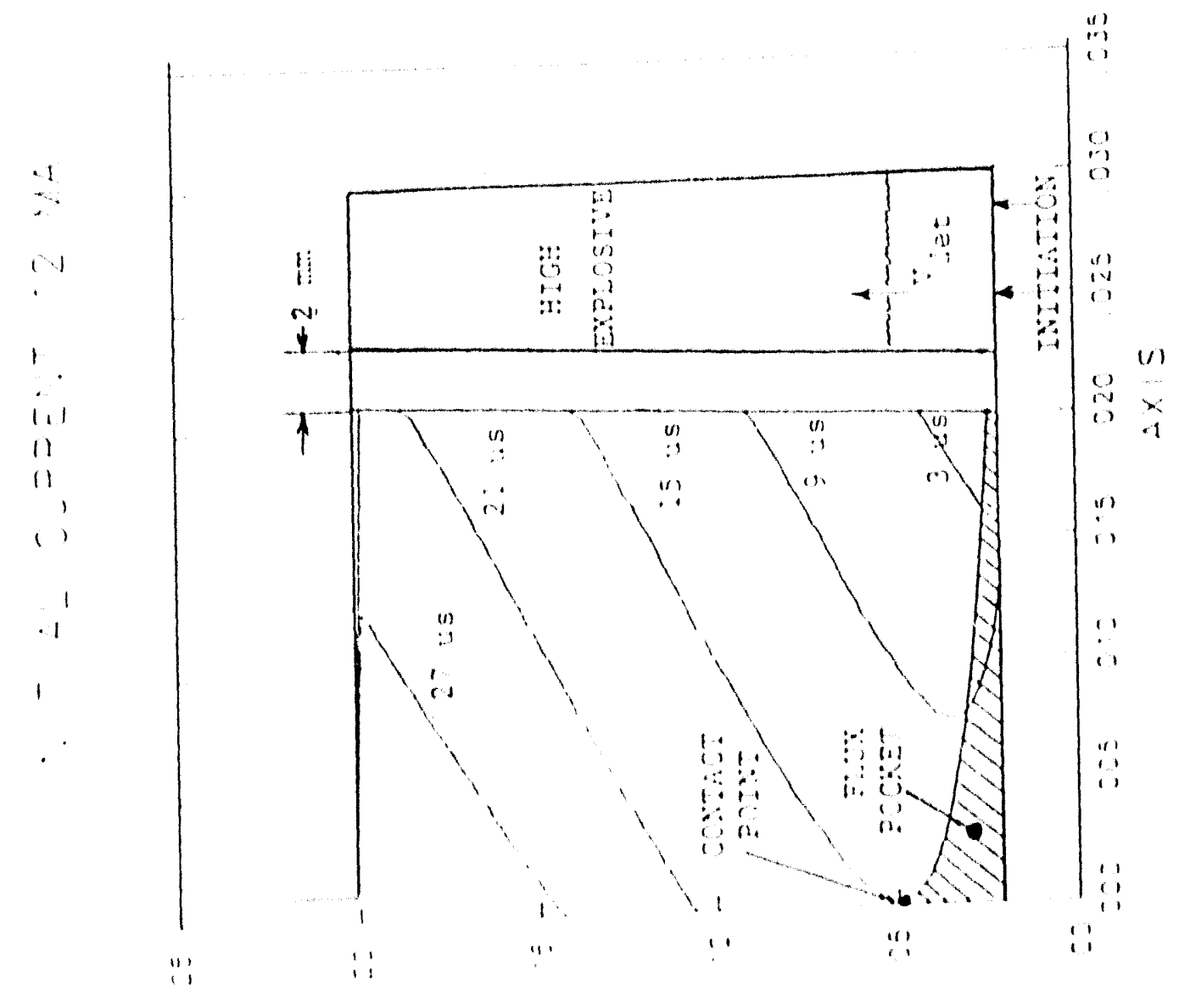

. I11 IVil

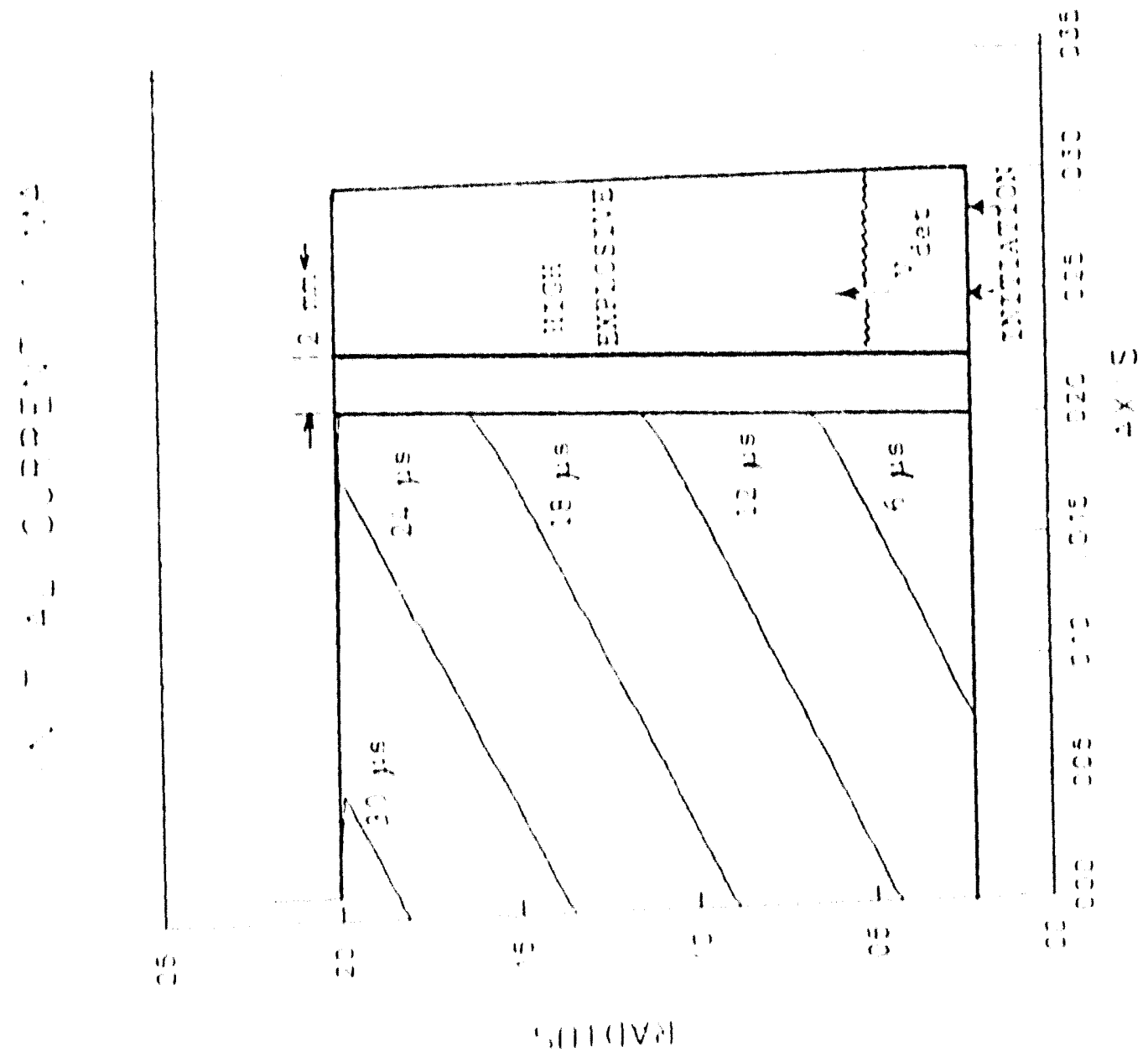




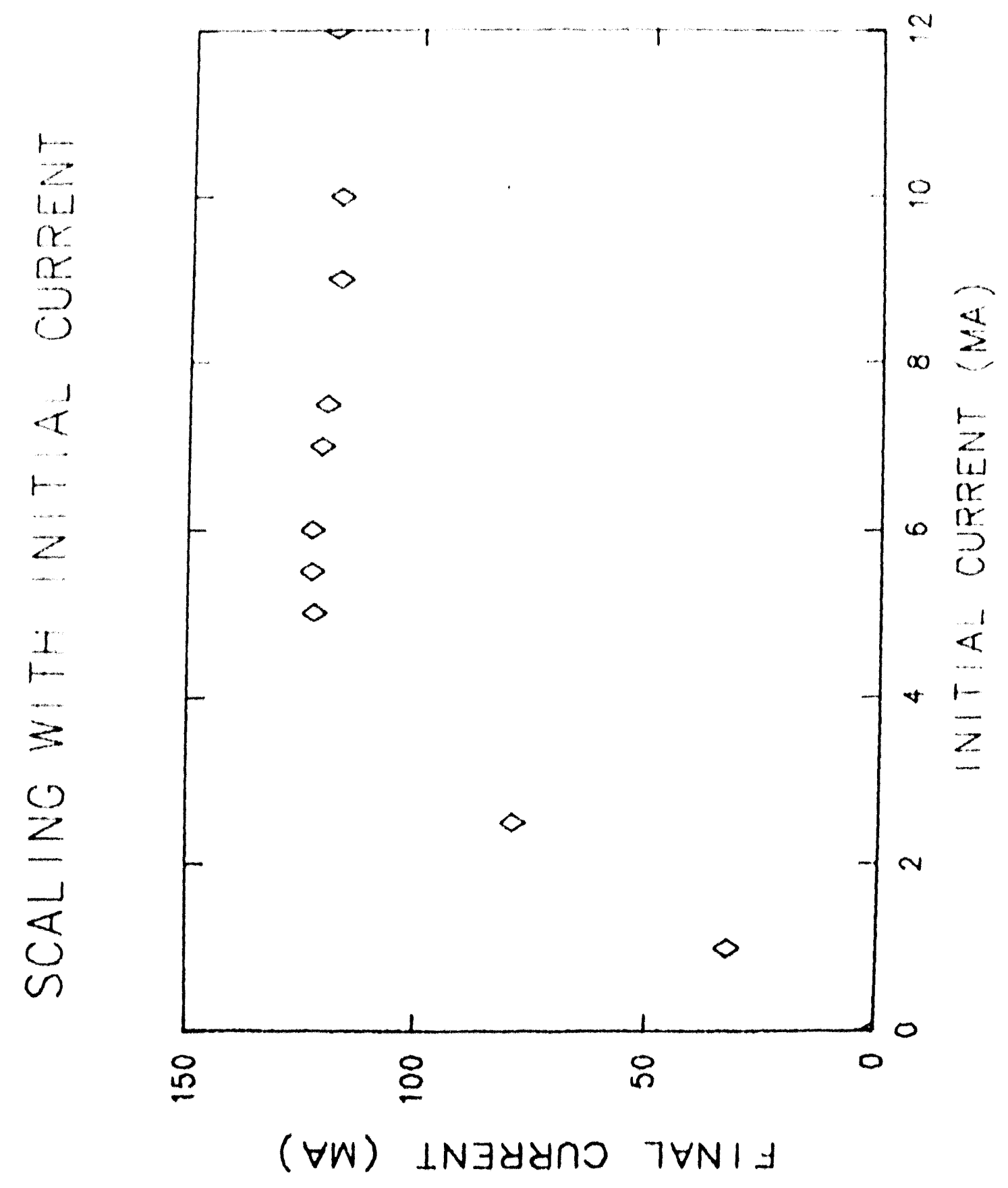



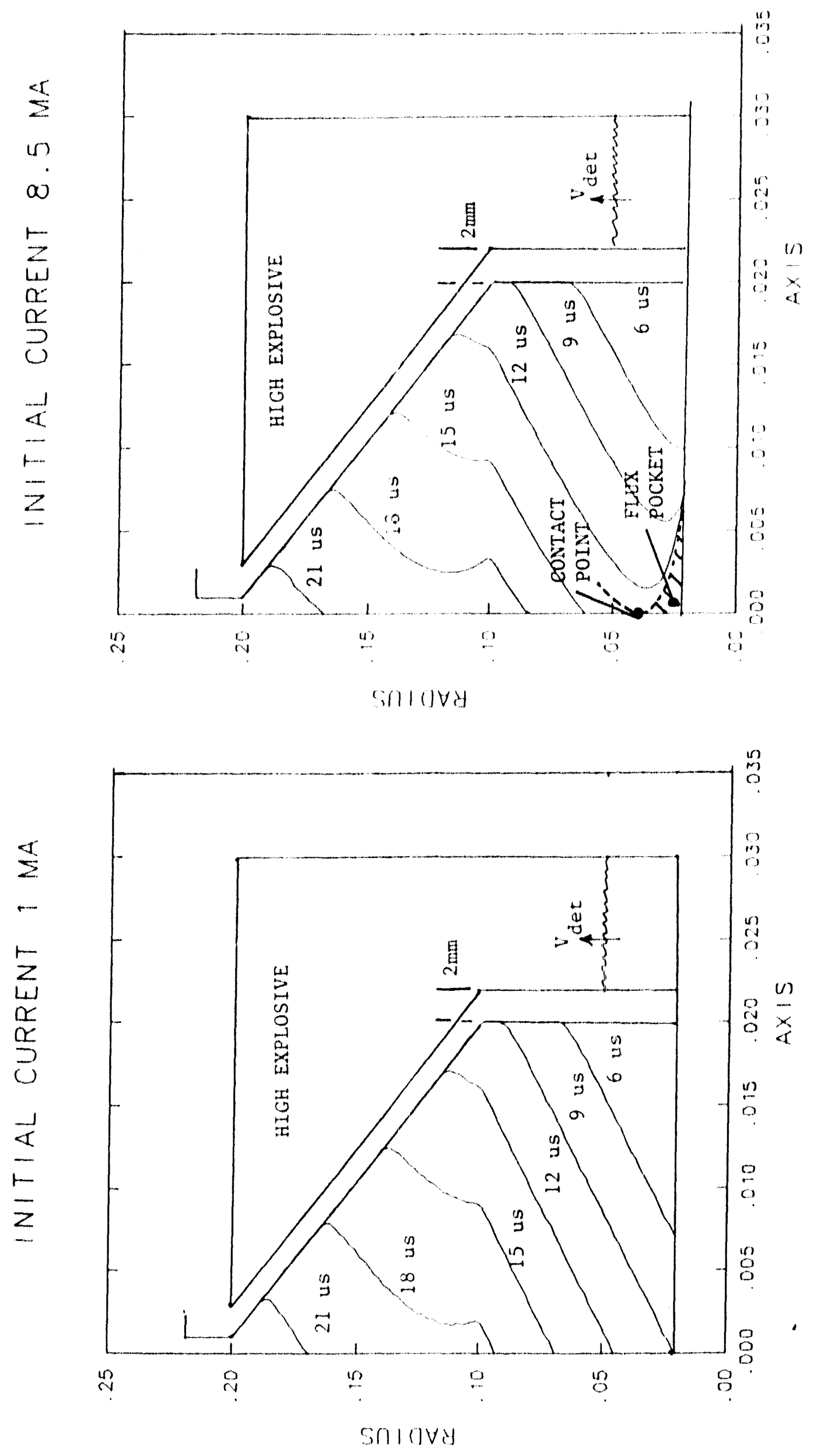

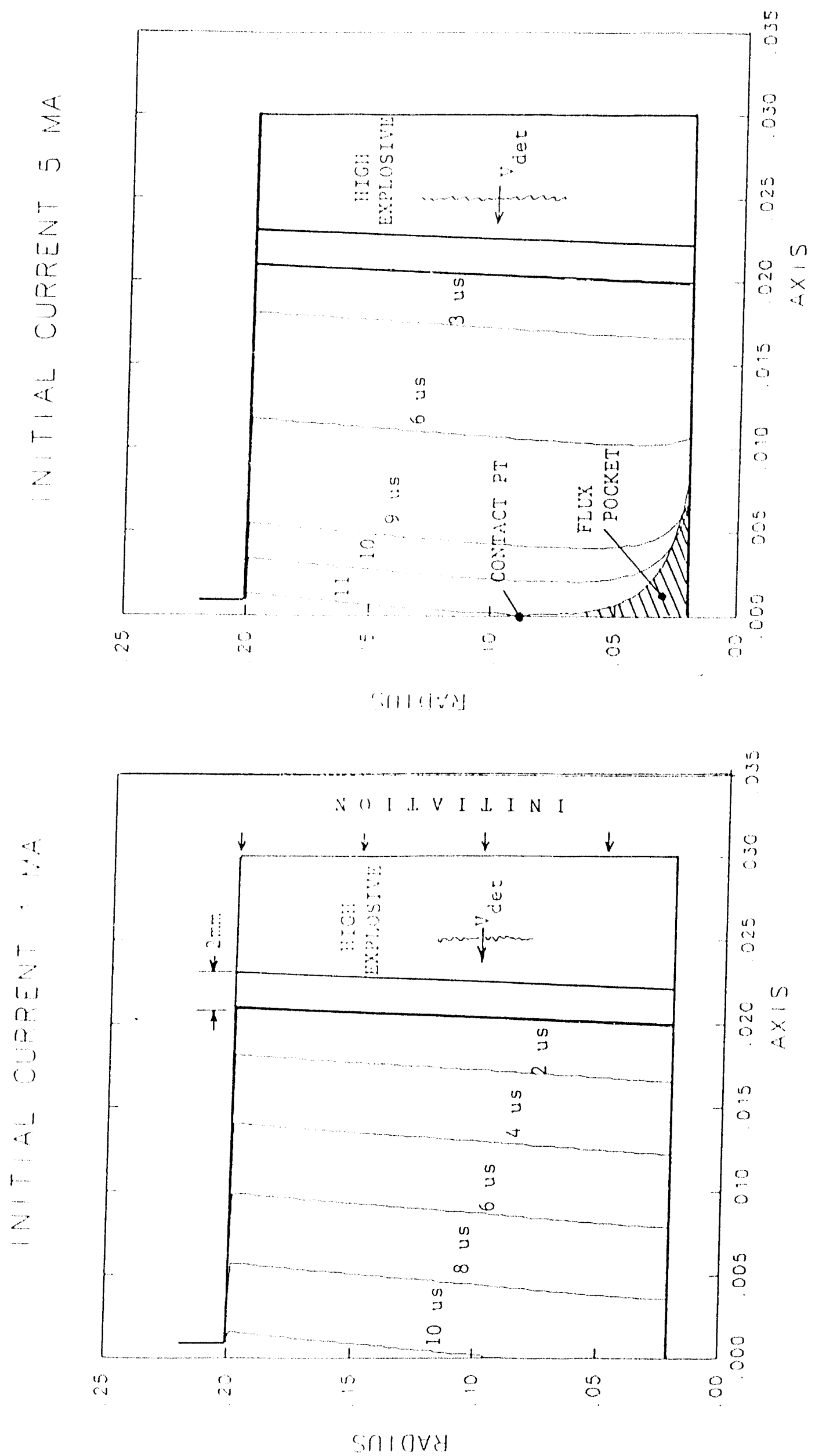

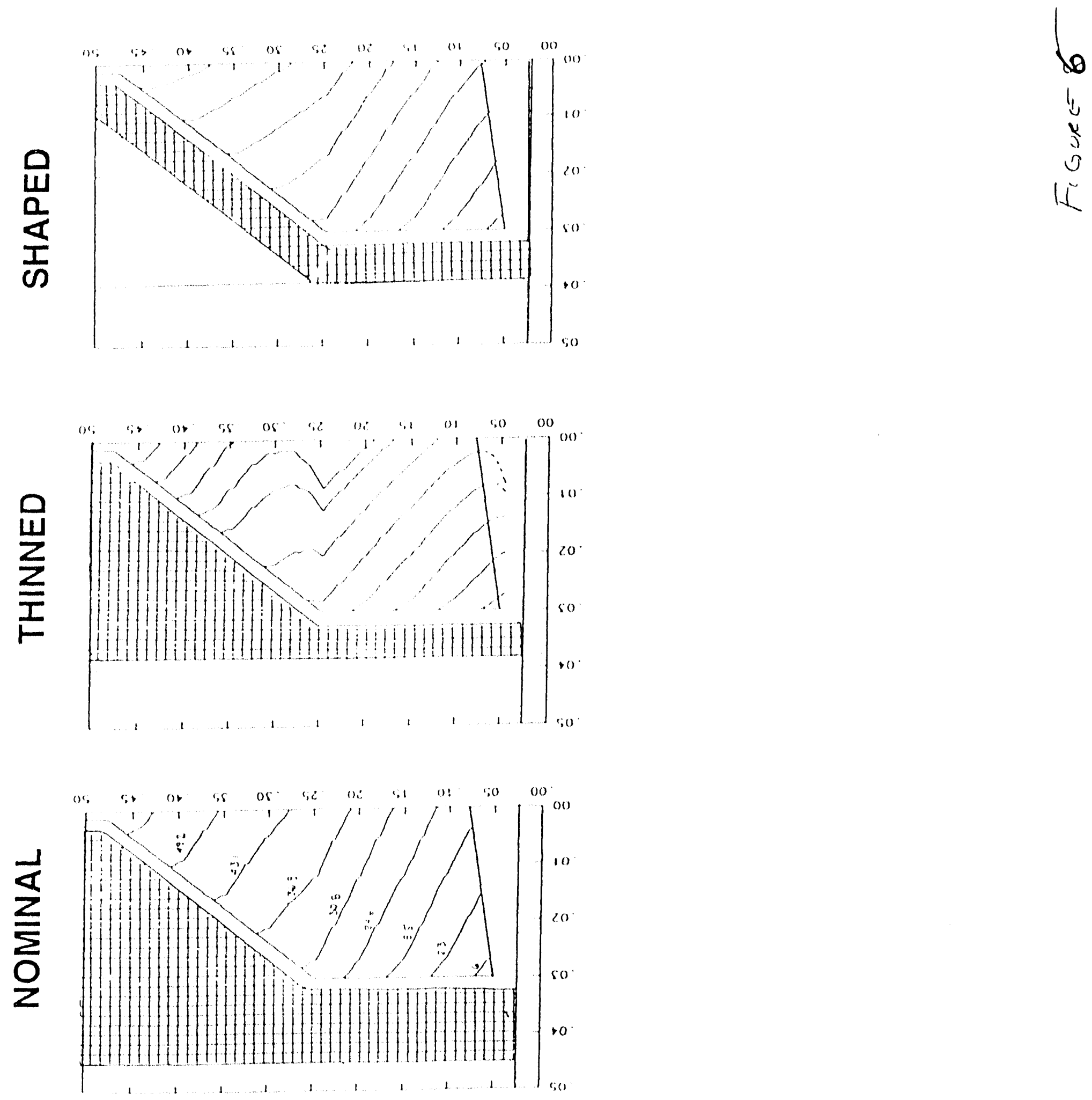
造

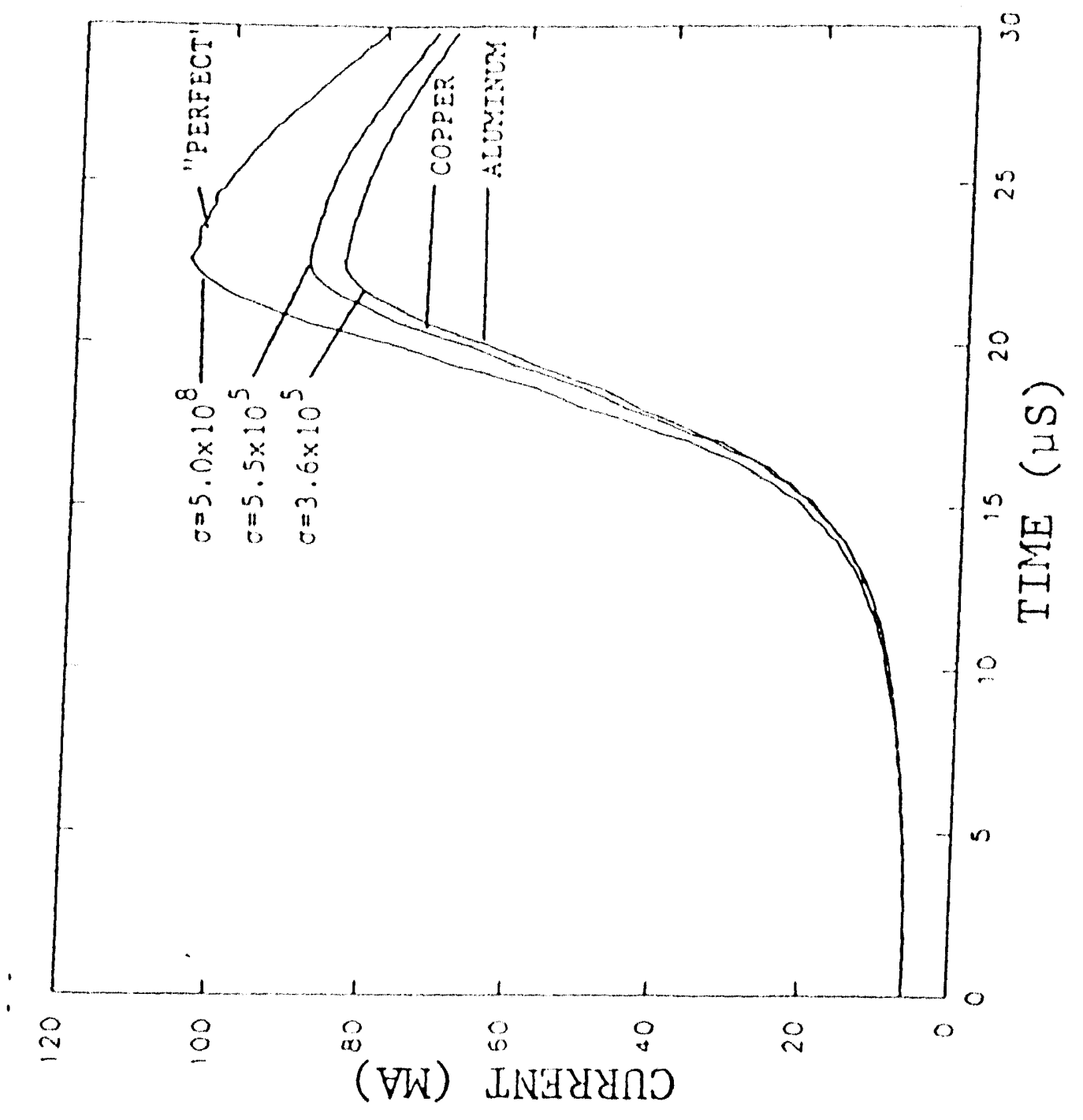


(1)

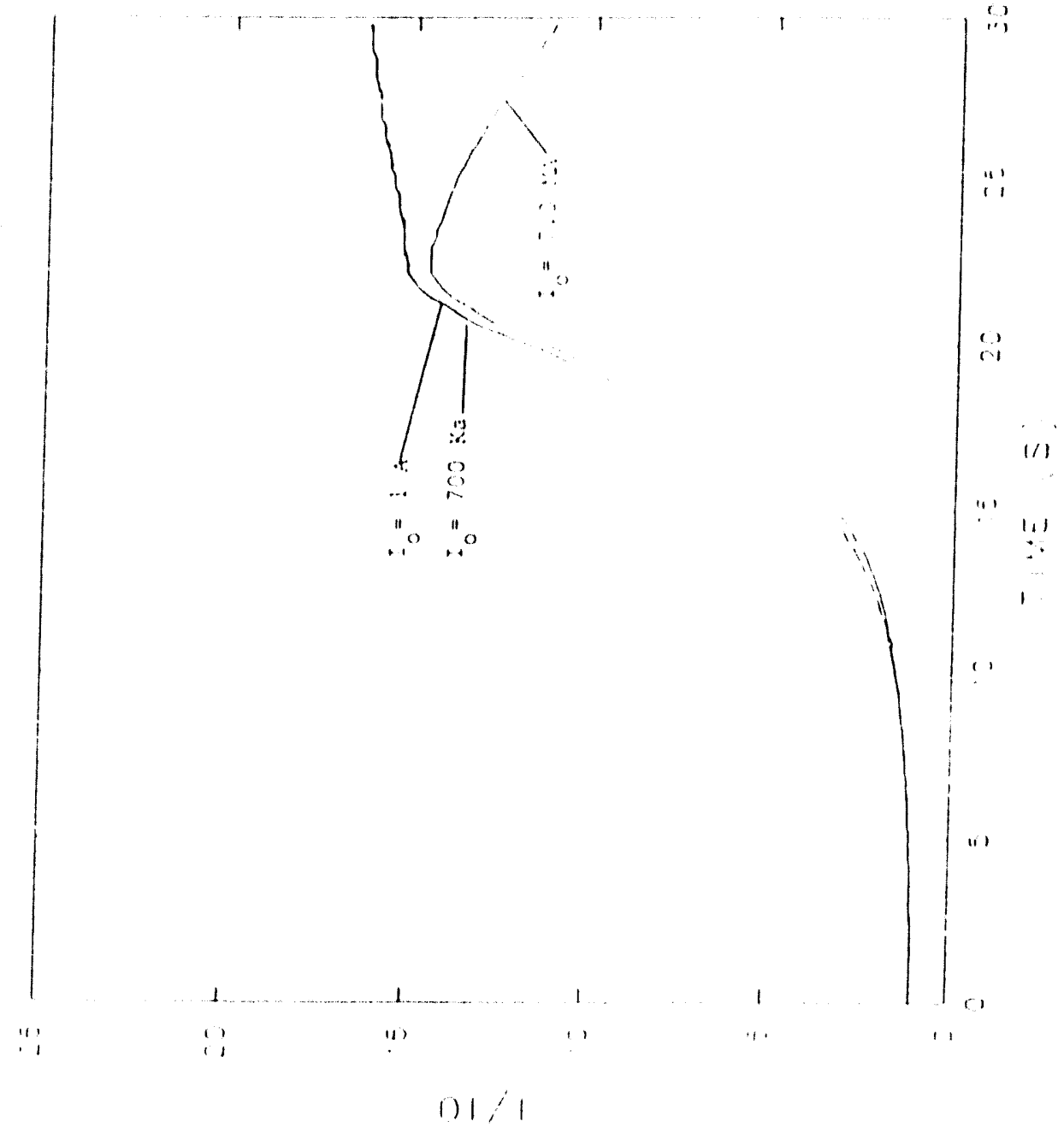



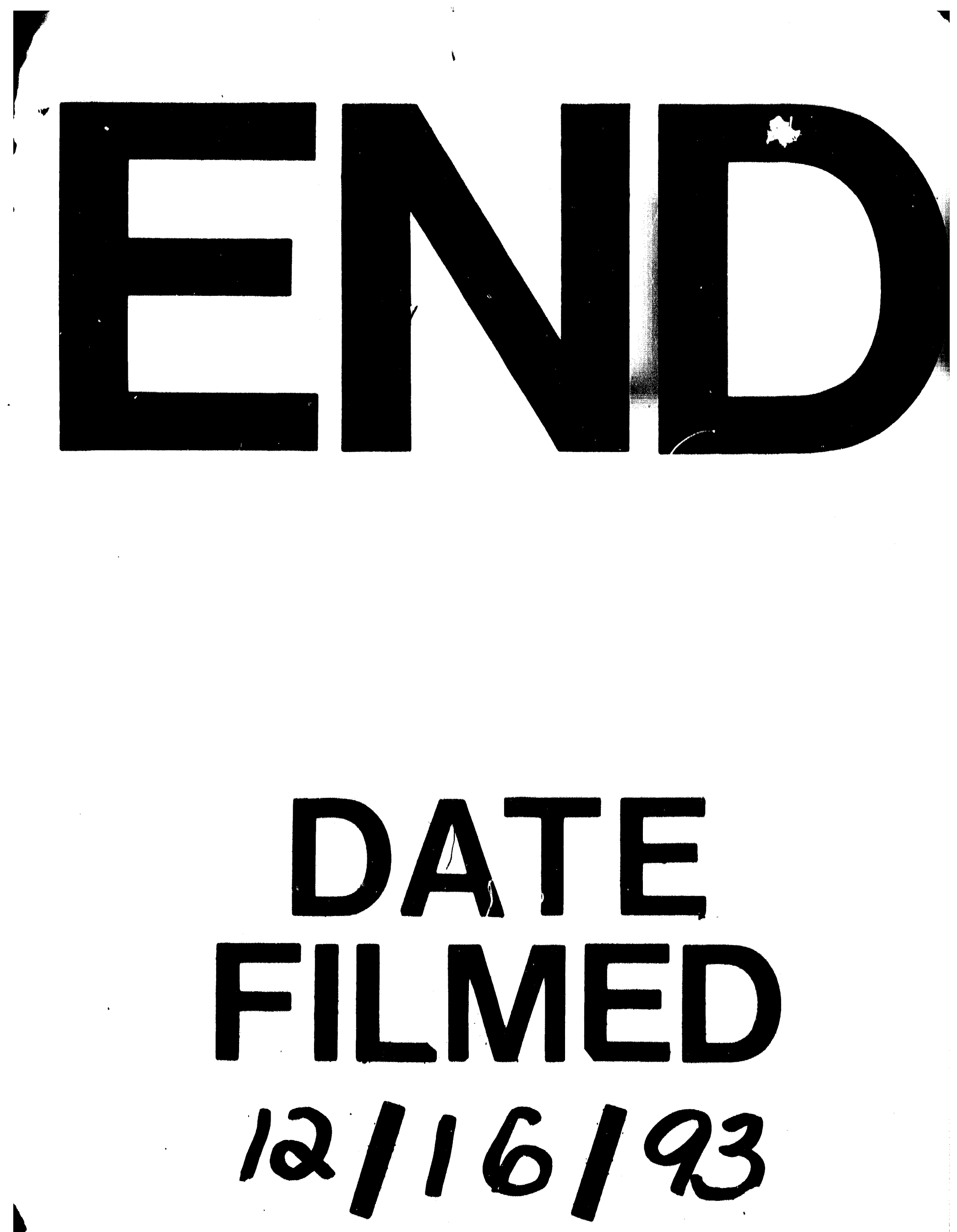

1 
$\mid$ 